\title{
A METHOD FOR DETERMINING THE ENVIRONMENTAL FOOTPRINT OF INDUSTRIAL PRODUCTS USING SIMULATION
}

\author{
Erik Lindskog \\ Linus Lundh \\ Chalmers University of Technology \\ Product and Production Development \\ SE-41296 Gothenburg, SWEDEN
}

\author{
Jonatan Berglund \\ Y. Tina Lee \\ National Institute of Standards and Technology \\ Engineering Laboratory \\ Gaithersburg, Maryland, 20899, USA
}

\author{
Anders Skoogh \\ Björn Johansson \\ Chalmers University of Technology \\ Product and Production Development \\ SE-41296 Gothenburg, SWEDEN
}

\begin{abstract}
Effective assessment and communication of the environmental footprint is increasingly important to process development and marketing purposes. Traditionally, static methods have been applied to analyze the environmental impact during a product's life cycle; however, they are unable to incorporate dynamic aspects of real world operations. This paper discusses a method using Discrete Event Simulation (DES) to analyze production systems and simultaneously enable labeling of products' environmental footprint. The method steps include data management, determination of environmental footprint, and communication of the results. The method is developed during a case study of a job-shop-production facility. To evaluate the DES method, the DES results were compared with the results of a Simplified Life Cycle Assessment (SLCA) conducted on the same production system. The case study demonstrates the possibility for the DES method to determine the variation between products in terms of the environmental footprint and highlights some of the difficulties involved.
\end{abstract}

\section{INTRODUCTION}

Companies today are becoming increasingly interested in measuring and reducing the environmental footprint of their products and activities. This interest is driven by both marketing possibilities and pressure from society. Companies are beginning to recognize the possibility of increasing their market share by acting before their competitors and taking the lead in this growing marketing area (Haanaes et al. 2011). From a legislative point of view, the pressure is increasing from society to declare the effect of products and activities on the environment. Previous studies have shown that by conducting such environmental assessments, companies can save money and reduce resource usage since the analysis can highlight large resource consumers as well as improvement opportunities (Max 2009).

Today, companies apply environmental assessment studies of their products and activities to support emission trading, marketing, and tax credits. According to a recent survey, a majority of retailers within the "Industrial Goods and Machinery" sector believe that it is necessary to pursue sustainability strategies to be competitive in the future market (Max 2009; Haanaes et al. 2011). 


\section{Lindskog, Lundh, Berglund, Lee, Skoogh and Johansson}

Life Cycle Assessment (LCA) is a well-known and fairly mature method for studying the life cycle of a product or service (ISO 2006a). Simplified Life Cycle Assessment (SLCA) is an emerging term to describe more compact adaptations of LCA, made for faster execution (Hochschorner and Finnveden 2003). Traditional sustainability assessment methods use mostly static data for calculations and do not consider the dynamic factors of the manufacturing processes. The use of static data results in average values as the outcome of the studies, as well as the need for a number of simplifications that could significantly impact the validity of the results (Reap et al. 2008b).

Discrete Event Simulation (DES) is a method often used to assess and optimize the performance of production systems. DES uses a digital model of the system being studied to predict the system's behavior given a certain set of inputs. The prediction is arrived at by sequential execution of events in the digital model, each event being causally dependent on previous ones. The dynamic capabilities of DES modeling provide the possibility to capture variations in the outcome and also to evaluate the effects of changes to the manufacturing processes. (ISO 2006a; Shao, Kibira, and Lyons 2010; Balci 1990; Heilala et al. 2008) However, there are some issues that need to be addressed in order to combine DES modeling with environmental studies and make it a feasible alternative to the traditional approaches.

This paper will discuss the difficulties associated with combining DES and environmental studies and illustrate how these difficulties can be managed through using an industry case study. The following section provides some background to the fields of LCA and DES. The paper then goes on to describe the case study methodology. Section 4 holds the SLCA and DES study results and the subsequent comparison of the two approaches. The method for calculating the environmental product footprint using DES is formalized and described in section 5. The paper ends with some discussion, conclusions, and notes on further research topics.

\section{CONCEPTS OF SUSTAINABILITY ASSESSMENT AND SIMULATION}

Currently, there are many different approaches towards environmental assessment being researched in parallel efforts throughout the scientific community. The following sub-sections discuss the assessment methods from both static and dynamic perspectives.

\subsection{LCA methods for determining environmental footprint}

Various static methods for analyzing environmental footprint have been around for some decades. LCA is one example of a static method for the environmental footprint assessment. LCA is also one of the currently most documented and standardized methods available. The method is designed to account for all emissions released to the environment from activities throughout the life cycle of a product or service; both products and services referred to as functions in LCA terminology. A properly conducted LCA considers all stages of a function's life cycle, in the case of a produced part this encompasses material extraction, manufacture, transportation, usage, and end of life. Such a study is often referred to as a cradle-tocradle or cradle-to-grave study, depending on whether or not the end of life stage includes any recycling. Another often used terminology is cradle-to-gate, which implies that the use stage and end of life emissions are not being considered. An LCA consists of four phases, namely, goal and scope definition, inventory analysis (or Life Cycle Inventory (LCI)), impact assessment (or Life Cycle Impact Assessment (LCIA)), and interpretation. Although LCA had been standardized by the International Organization for Standardization (ISO) in 1997, it is still evolving and was revised in 2006. (ISO 2006a; ISO 2006b)

Besides the LCA standard, there are several other notable efforts which are trying to solve parts or aspects of more or less the same problem. Another ISO initiative, for example, is the ongoing development of ISO 14955, a standard for environmental assessment of machine tools (ISO 2011). The Product Category Rule (PCR) and Environmental Product Declaration (EPD) efforts are more closely related to the actual product (EPD 2011). PCR is a way to formalize the requirements of an environmental assessment study based on the concerned product type. EPD is the implementation of the PCR protocol on a se- 
lected product. EPDs are based on ISO 14025:2006, which concerns environmental labels and declarations (ISO 2006c).

SLCA is an emerging term that denotes any LCA study that does not meet one or more of the requirements of a full-scale quantitative LCA study. Simplifications can range from limiting the scope or using large amounts of secondary data, to not performing the end point impact assessments. Some formalized SLCA methods can be found in Hochschorner and Finnveden, 2003.

One of the strengths of LCA is that it is widely known and has a broad community surrounding it; therefore there are numerous potential peers available to perform study reviews, a key step in the methodology. As a result of its disregard for temporal aspects, LCA often requires an average value for the environmental emissions of a function. This is a potential source of inaccuracies in a dynamic and ever changing production environment. The assumption of linearity in LCA calculations is another source of concern, especially in a setting with demand variations. Reap et al. (2008a) and Reap et al. (2008b) provides a more exhaustive overview of identified issues within the subject of LCA studies.

\subsection{DES methods for determining environmental footprint}

Simulation has traditionally been used to assess the performance impacts of system changes, or to develop plans for changing a system in order to enhance its performance. In recent years, simulation has been proposed as a viable technique to improve environmental assessment. Several studies illustrating the capabilities of DES as a tool for dynamic assessment of a product's environmental footprint exist (Shao, Kibira, and Lyons 2010). DES enables its user to define a freely chosen set of output parameters, which could cover economical as well as environmental aspects. Simulation supports cost and environmental assessment by accurately tracking related data at the location of parts in a system at any given time. This feature enables users to allocate overhead costs, such as area heating or cooling, lighting, and other auxiliary resources at a very detailed level (Lindskog and Lundh 2011).

DES is a growing practice that, similar to LCA, requires experience and domain area expertise. It is still hard to exchange DES models between users and many models suffer from high complexity, resulting in models that are less often re-used or updated, which neglects one of DES's potentially strongest benefits. Ongoing efforts aim towards standardizing simulation methodologies to make them more repeatable and interchangeable; the Core Manufacturing Simulation Data (CMSD) standard is one such effort, which became a Simulation Interoperability Standards Organization (SISO) standard in 2010 (SISO 2010). Another current effort aims to incorporate activity based costing (ABC) principles into DES models, simplifying and enabling the technique to a broader group of users (Andersson et al. 2011).

When using dynamic methods, differences that occur over time become visible and traceable. This can help to increase the understanding of the uncertainty in otherwise averaged values (Campanelli, Berglund, and Rachuri 2011). One of the concerns with DES is the amount of data collection that is required. Some studies indicate that about $30 \%$ of the time in a DES project is spent on collecting data and other data-related activities, such as cleaning, formatting, and statistical fitting of the data for use in DES applications (Skoogh and Johansson 2009). However, this drawback could potentially be offset if the dynamic environmental analysis is conducted in parallel with, or as an addition to, a DES effort that is already required (Andersson et al. 2011).

\section{CASE STUDY METHODOLOGY}

The case study compared the DES and SLCA methods for determining the environmental footprint of an assembled product consisting of in-house machined metal parts and bought components. Results from the case study were used as a basis for proposing a method within the area of DES and sustainability. The main scope has been defined as the production of components within a single factory of a company and the supporting external processes. The other parts of the production chain from cradle-to-gate were examined in a static manor. For analysis purposes three process groups were defined. These are, as shown in Figure 1, "Before Production," "During Production," and "Transports." Each process group is further de- 
composed to allow better tracking of emission sources. "Before Production" includes extraction of raw materials for the components that are produced and assembled in the factory. "During Production" includes any auxiliary resources such as coolant oil, weld gases, heating of the factory, and energy consumption during production processes. "Transports" includes deliveries by truck from the suppliers to the external process providers, and to the customer. Customer operations and use stage are not considered.

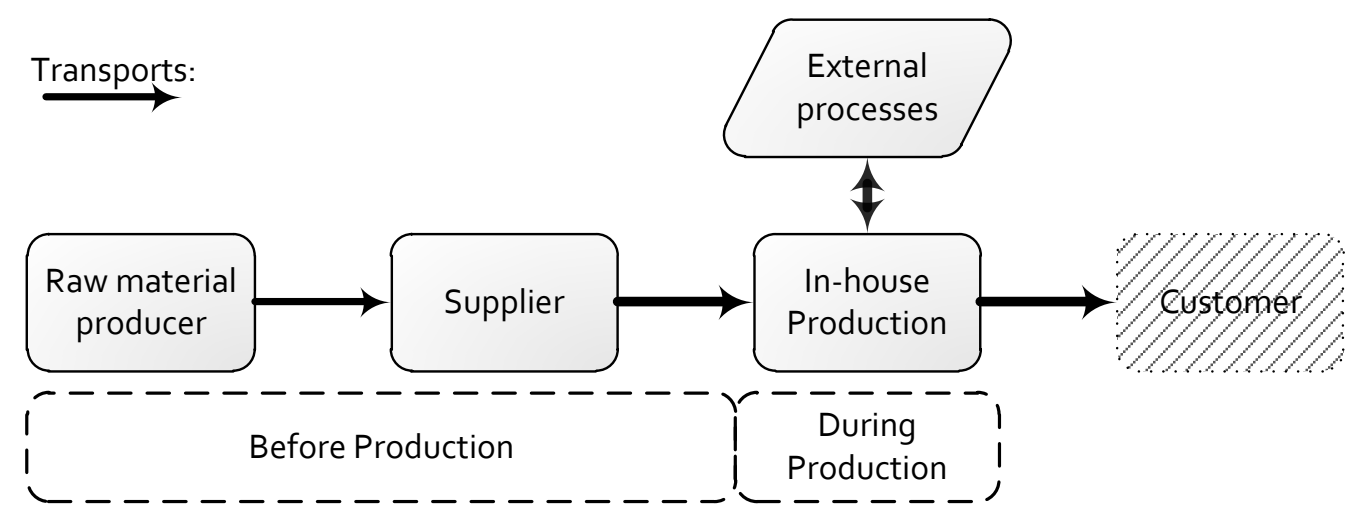

Figure 1: Case study scope and main emission drivers

\subsection{System description}

The case study manufacturing company employs around 20 employees, and its main products are machined metal parts. Produced parts range from standard components to special orders. Because of high variation in products, the shop floor is built around stand-alone machines and the flow through the factory changes depending on the current product's manufacturing process. Most of the production planning and economics are controlled through an Enterprise Resource Planning (ERP) system. Using this system the logistics manager and the production planner can plan the work that is going to be carried out each week. The purchasing manager and the sales manager also use this system to keep track of when and to/from whom the materials and finished products are being sold/bought.

\subsection{Work procedure}

The case study was implemented through four main progress phases, which are described in Figure 2. Product and production processes data were gathered as a first phase. Based on the gathered data, two parallel works were performed. The DES study and the SLCA study used the same input and environmental data to ensure that differences in their results stemmed from the methodology and not from the data. Results from the two methods were compared to benchmark the proposed DES method.

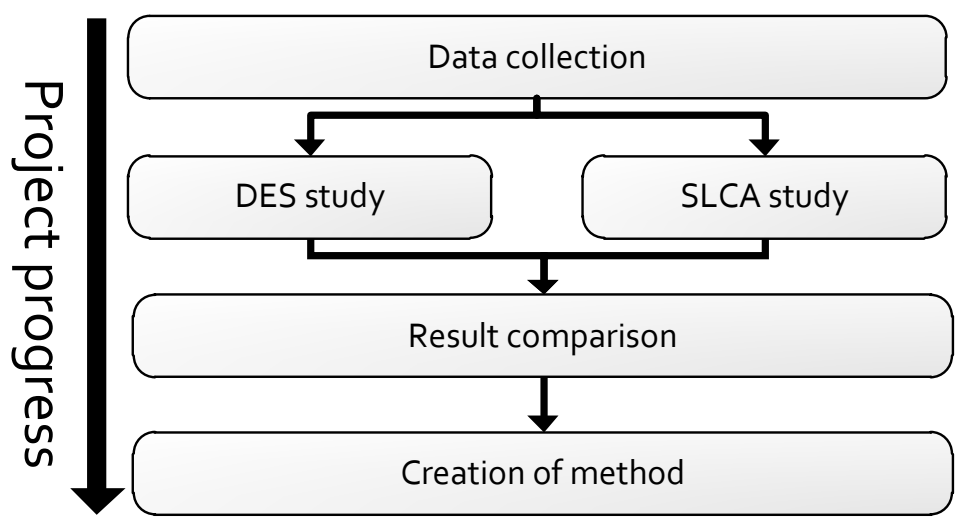

Figure 2: Project progress 


\subsubsection{Data collection}

Data collection is a time consuming and important phase in environmental footprint studies (Skoogh and Johansson 2008). General material data such as quantity and supplier information were collected through the company's ERP system in addition to invoices from 2010. In the ERP system it was possible to find product structures and production flows within the factory. Delivery dates of customer orders were accessed from the same system. Transport distances to suppliers, external providers, and the costumer were calculated by a common route finding web applications for the shortest route. The electrical power utilization for machines was analyzed by a power quality monitoring instrument. Data from at least four cycles of machining products were collected from each machine to get qualitative values. Collected values were categorized into idle and busy states and average values were calculated.

The weights of components needed to produce the studied product were measured. Components machined within the factory were measured both as finished components and as raw materials. In the case where no raw material was available, the distributor's product information was used together with the raw material dimensions to get the original weight of the raw material pieces. Interviews with operators were made in order to gather data about production problems such as breakdowns and repair times. The interviewees also answered questions about the production system in general and how the operators handle exceptions in the production system.

Process life cycle data were extracted from the LCI databases ecoinvent (one of the world's leading commercial LCI databases, maintained by the Swiss Centre for Life Cycle Inventories) and the European Reference Life Cycle Database (ELCD). Raw data were used with regard to the functional unit of the process or material. When LCI data were gathered, no specification of production location was made. The databases contain a large number of emission factors for most processes and materials. In this case study, only a select few were extracted $\left(\mathrm{CO}_{2}, \mathrm{SO}_{\mathrm{X}}, \mathrm{NO}_{\mathrm{X}}, \mathrm{CO}\right.$, and $\left.\mathrm{CH}_{4}\right)$.

\subsubsection{DES method}

To enable analysis of a realistic dynamic system, the methodology incorporated a DES model. A conceptual model was created with data collected from the production system, such as layouts and production flows. The model only contained resources used for producing and assembling the studied product and its components, other resources were only included as static 3D objects for graphical representation. The focus was directed towards evaluating the emission drivers, with no consideration of productivity, which is normally analyzed in a DES study. The logic was designed for determination of emission drivers for each component as it is processed by a resource, which makes it possible to study each final product's and the total production's emission values.

Relevant input data was accumulated in a spreadsheet and imported as values into the DES model. The output data from the model was exported to an output spreadsheet after each run. Environmental data from LCI databases, raw material data, factory overhead costs, and transport distances were left out from the model and included in the output spreadsheet as static values. Calculations in the spreadsheet were used to obtain the average values with a standard deviation of the environmental product footprint for the population of one year's worth of production.

Verification of the DES model was made continuously by studies of critical processes in the actual production and comparing them with processes in the model. Production data such as lead times from the model were compared with real times from the production for validation purposes. Data that could be connected to each process were used, for example electricity consumption for each machine in idle and busy state. Emission sources that did not derive from machine usage, such as heating and cooling fluids, were divided among each product as overheads in the output spreadsheet. Their contribution to the product was calculated from an overhead percentage based on resources that were tied to the product and the total amount of resources available in the factory. Some of the resources were: sales figures, storage 
space, and material weight. Several overhead percentages were found in this case study but no evaluation of the appropriateness of their use was made.

\subsubsection{SLCA method}

The SLCA for the case study covered the cradle-to-gate life stages of the studied product: raw material acquisition and manufacture, including related transports. Consideration was taken for direct and indirect emissions resulting from the manufacture of the product. The LCI data utilized were retrieved from the ecoinvent database. The internal processes of the factory were all combined into a black box and factory level resource usages were allocated to the product.

Inputs to the system included raw material and components from sub-suppliers, electricity, oil for coolant and lubrication, paint, and welding gases. In accordance with the ISO 14040 series, and because no data for more exact methods were available, allocations were made with regards to the product weight. The allocation figure was calculated as the weight of the product's ingoing components and materials divided by the total amount of raw materials and components consumed by the factory over the period of one year. Electricity consumption was averaged over one year of production. It should be noted that the heating of the factory adds a significant contribution to its total energy consumption during winter.

\subsection{Comparison of the two methods}

The normal DES model validating procedure compares the model results against the real system. In this case, focusing on the environmental performances of the system, the validation was performed in a different form but using the same techniques proposed for validation of simulation models (Sargent 1999). To validate and evaluate the results of the DES model, it was compared to the SLCA study. This comparison also highlights the differences in how data is treated and calculated.

The comparison focused on how the methods results differ through the used data. Results from the different methods are central in the comparison. Basis for the evaluations was focused towards one of the end products of this project, the labeling of a product. To make the two methods comparable, the incoming material weight was used to allocate the overhead in both studies.

\section{CASE STUDY RESULTS}

The production directly controlled by the company, presented as "During Production," shows similar emission values for both the DES study and the SLCA study. The similarities were expected because the two studies originate from the same input data and calculations for static emission drivers. In Figure 3 the DES result shows variation between each produced product in comparison with the static SLCA value. Based on the variation in the DES result it is possible to calculate a standard deviation and evaluate production fluctuations.

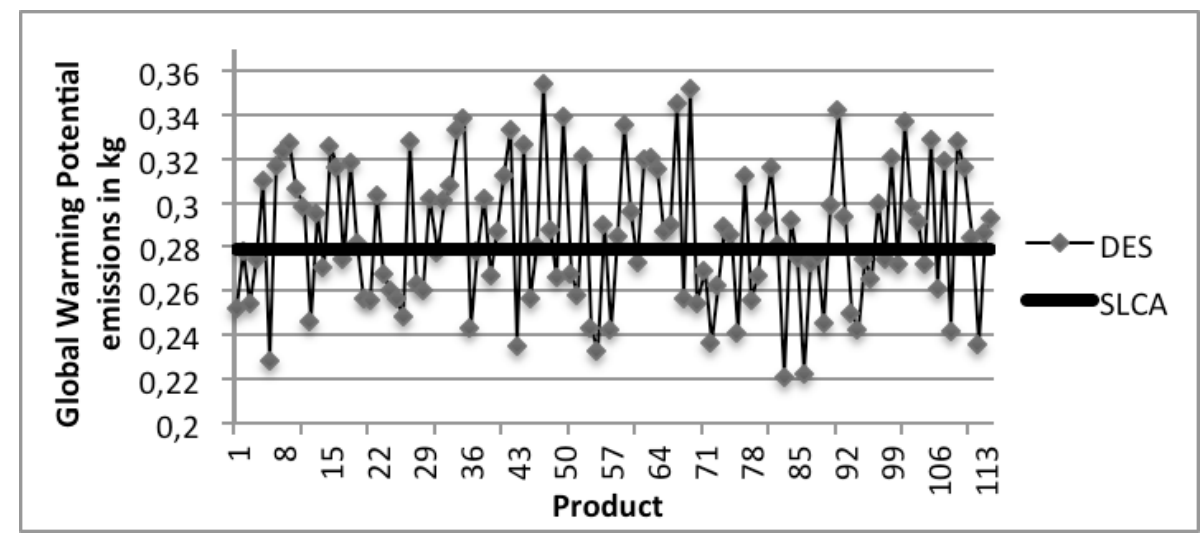

Figure 3: The variation of GWP emissions for 114 individual products 


\section{Lindskog, Lundh, Berglund, Lee, Skoogh and Johansson}

"During Production" consists of different parts in the two case study methods. The first part consists of the internal processes, which are directly connected to the simulation model and account for the amount of resources each product consumes in the production. The overhead part includes static parameters that are connected to the production facility, such as energy for heating and other supporting equipment. External processes are also included in the "During Production" emission driver, which consists of surface treatment made by a third party. The SLCA includes the external processes along with the internal manufacturing. The internal manufacturing is seen as a "black-box," which includes all incoming resources of the case study. The interesting parts are how the production dynamics change the output data for the processes within the production. Variations could have a significant effect on the result and are not accounted for in the SLCA method. The standard deviation can be observed in Figure 4 and Figure 5 as a thin black bar on top of the DES results.

In the comparison, two electricity sources were studied. The environmental impact was characterized by its global warming potential, a measure of the heat trapping potential of green house gases such as carbon dioxide and methane. As seen in Figure 4, $100 \%$ hydroelectricity was used, which represents the current situation. When changing the electricity source to mixed (ELCD data for a Swedish mix consisting of $46.3 \%$ nuclear, $45.6 \%$ hydro, $2.5 \%$ biomass, $2 \%$ heavy fuel oil, $1.6 \%$ hard coal and $2 \%$ other sources), in Figure 5, emissions for during production were drastically increased. The SLCA result was affected the most by the change and moved outside one standard deviation of the DES result, which suggests that the two methods consist of different amounts of electricity consumption. In the case study the variations become less important when static overhead emissions are a larger contributor to the product's total emissions. External processes are not affected by the change and become a very small part of the during production part.

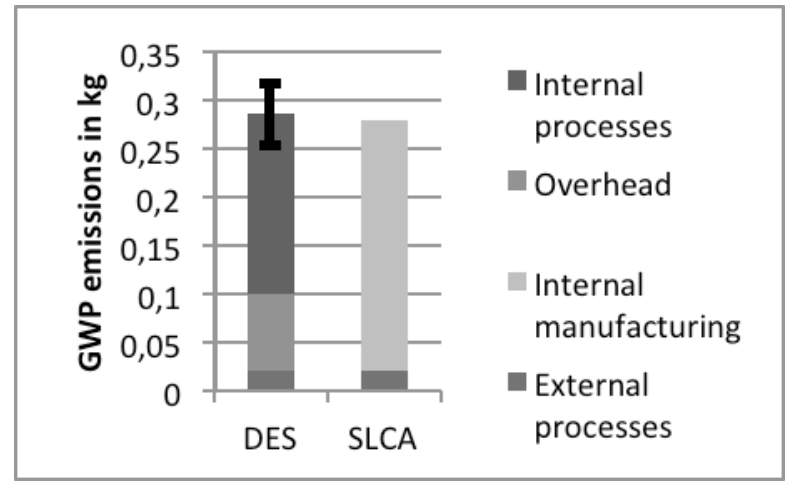

Figure 4: Average per product emissions for the "During Production" stage during one year of production using $100 \%$ hydroelectricity

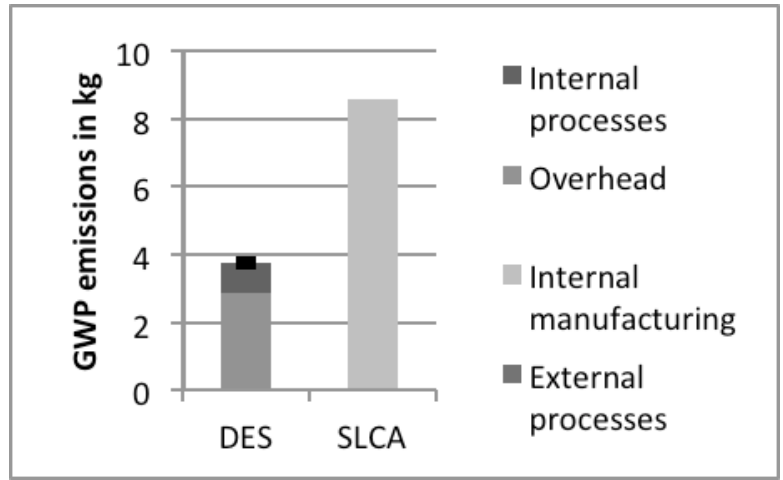

Figure 5: Average per product emissions for the "During Production" stage during one year of production using mixed source electricity

The SLCA study accounts for the factory's total electricity consumption and will indicate higher consumption attributed to the product. Average electricity consumption allocated to each product in the DES study is $34.45 \mathrm{kWh}$ compared with $83.68 \mathrm{kWh}$ allocated in the SLCA study. This different consumption originates from the allocation method used for internal processes and the fact that several other products are produced in the factory with a variance in energy consumption.

\section{METHOD FOR ENVIRONMENTAL PRODUCT FOOTPRINT USING DES}

The case study revealed three general areas that are important for successfully determining environmental footprint for an industrial product. First, how the management and collection of data builds the foundation for the study and its results. Second, how DES can be used to determine the environmental product footprint. Third, once the product's environmental footprint has been determined, now the results can be communicated. 


\subsection{Data management}

Creating a dynamic model for determining the environmental footprint requires a lot of data to be collected and managed. These data can be divided into three groups according to the product's life cycle stages that are related to the studied production. To assess the environmental footprint, an additional fourth group is needed to cover the environmental properties of the data in the first three groups.

In Table 1, questions and data sets are gathered under their respective areas. If all data required by the list is present, then the base for the model is complete. Depending on the type of production to be analyzed, some of the questions or data sets can be excluded or presented in a different form. Process data might be added to create a complete model, based upon the practitioner's judgment. The finished product data are also important for determining how much material is scrapped during production.

Table 1: Questions and data sets required to assess an environmental footprint through DES

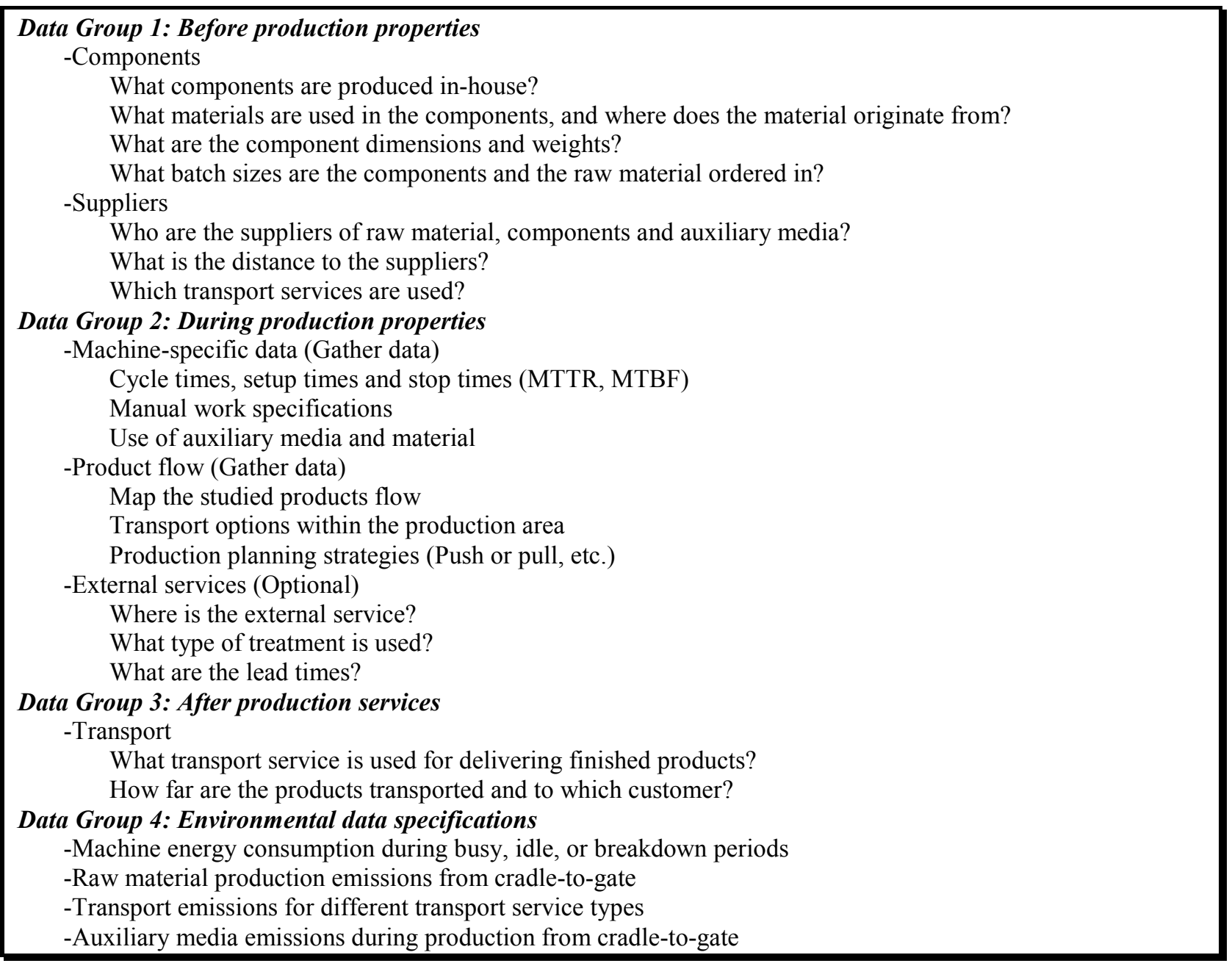

Managing these diverse data requires multiple documentation formats to make it comprehensive. Pictures over the product flows and tables for machine times are two methods used in the case study. The chosen documentation format(s) should easily integrate with the simulation software.

\subsection{Determine the environmental footprint}

Banks methodology is a well-adopted method for producing a verified and validated DES model. (Banks 1998) This methodology can be adapted when determining the environmental footprint of a product. To determine the environmental impact the simulation model has to be created. This step during the project is 
often software specific and the choice of software could be done with regard to the task, the data or the stakeholder's usability of the model. Depending on which software is chosen there might be an available plug-in that can handle most of the environmental calculations automatically. Using a plug-in might however reduce the control of data calculations.

If the model is created without any environmental plug-in the dynamically generated data should be added to each product on a machine level as exemplified in Figure 6. The static input of environmental overhead costs can be added within the simulation model or, to simplify the model, it can be added later in the data sheet that presents the output of the model.

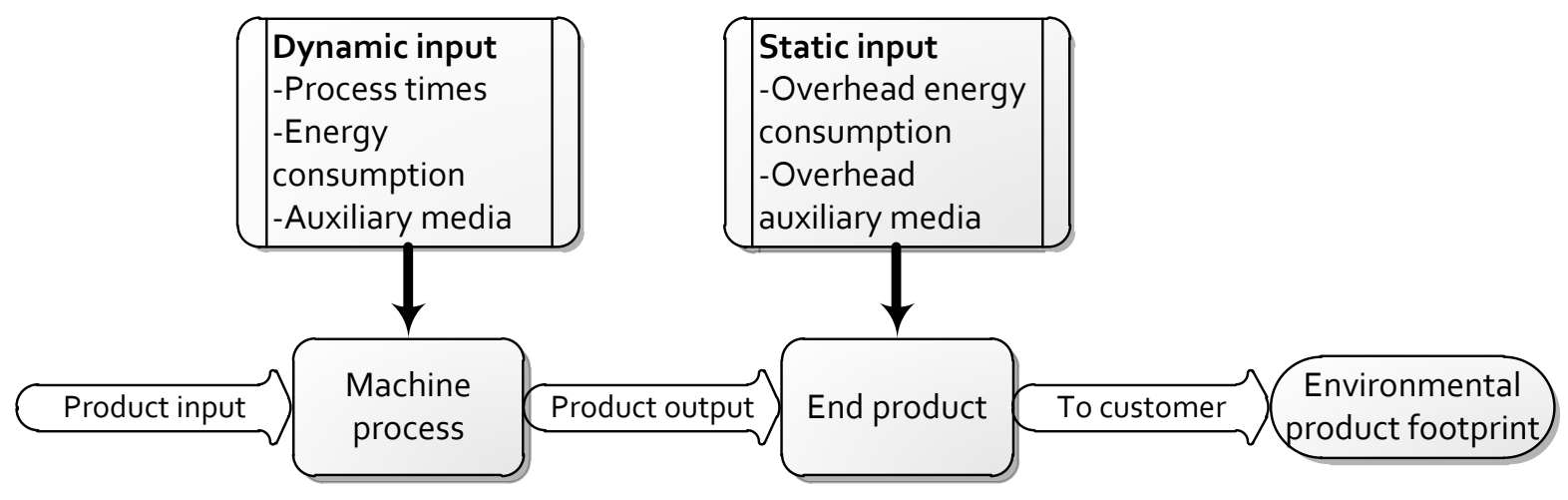

Figure 6: Dynamic and static environmental factors and data affecting a product's environmental footprint

Using this way of allocating dynamic and static environmental emissions or resources gives a total for each product. The end product's consumption will then consist of energy, materials, and media used during the production, which all produce environmental emissions. The output value for each individual product will not be the same because of the dynamics of the simulation model. Validating and verifying the simulation model can be done with several methods suitable for the project. The best possible practice is if the output result and production details can be verified against the real system through known validation methods. The environmental product footprint could be validated against another known method for determining environmental impact (Sargent 1999).

\subsection{Documenting and communicating the results}

To make the results credible, a thorough documentation of the work process is imperative. The documentation should facilitate third party review and verification by an independent organization. In practice, this could present difficulties, i.e. in providing transparency while protecting confidential information.

Depending on to whom the information is directed, the amount of information communicated from an environmental product footprint analysis can differ. This project has identified two main receivers of the environmental information: customers and the producing company. It is recommended that two different labels of the product's environmental footprint should be used, one simple yet informative label for the external customers and one more detailed label for internal communication and improvement.

For marketing purposes and possibly in anticipation of regulatory compliance, an external label could be created and communicated. This label should be directed towards customers. To deliver a message that will be intercepted among others, a simplified message is preferred. The authors are recommending one or maximum two values to indicate a product's environmental footprint.

It is recommended that the internal label should be divided into stages of the manufacturing process and other relevant activities. A stakeholder can be the production manager, production engineers, machine operators, or other relevant personnel. Relevant environmental factors included in the label have to be selected to match the production itself and the external label. 


\section{DISCUSSION}

The comparison between the DES study and the SLCA study reveals several similarities and differences. Most calculations made in the SLCA study are also accounted for in the DES study, for example "Before Production" and external processes. The comparison has shown that the main differences between the results of the two studies are found within the main emission drivers during production. The DES method could allocate parameters to each product, which is usually not detailed in an SLCA. However, detailed parameters of the DES study demand thorough data collection efforts to be accurate.

In a project with the goal of only determining the product's environmental footprint, it might not be beneficial to use DES because it extends the time needed for project completion. If a simulation model already exists or is supposed to be developed for other purposes, the addition of environmental parameters is not that time-consuming and will give more information to the stakeholders of the project. One of the greatest benefits of using the proposed method instead of a static method is that the variables in the system make it possible to allocate the dynamics to each product. It is also possible to analyze production stability and find sources in the system with high emission instability that could be improved. By focusing efforts towards the right emission source, the largest improvements can be made for the whole system.

The proposed method is specifically designed for an industrial case that is similar to the case study and its main stakeholders. To make the method more general, some parts might have to be included or excluded. For studies that are not concerning production of industrial products, this method might not meet the required objectives.

\section{CONCLUSIONS}

The variation in output results for individual products in the proposed method has shown to be its strongest asset when benchmarking against the static method, SLCA. This makes it possible to calculate a standard deviation and evaluate the production system in a way that is not possible with results from an SLCA study.

The job shop production setting in the case study has not shown to be optimal when using the proposed method because it involves decisions taken by the individual operators and it is difficult to gather dynamic data from the processes.

Before making a DES model of the production system, the purpose with the model should be analyzed. If the only aim is to determine the environmental product footprint or if the production system is complex it may be enough to make an SLCA study. But if a simulation model already exists or the purpose is to evaluate and improve the system the proposed method is recommended.

\section{FUTURE RESEARCH}

For future work in this area and within the EcoProIT project (EcoProIT 2011), the authors are aiming at the following areas of research:

- Provide clearer guidelines of how to use overhead allocations dynamically in future projects using the proposed methodology.

- Further research, aiming to determine time consumption for a study using the proposed methodology at a more appropriate production facility.

- Generalization of the proposed methodology for expanding the usefulness into other production settings as well as other processes.

- Generalization of an environmental product footprint label for use in commercial cases.

\section{ACKNOWLEDGEMENTS}

The funding for this research is granted by Norrahammars Mekaniska Werkstad (NMW) and ProViking through the EcoProIT project. The work described was also funded by the United States Government and 
is not subject to copyright. No approval or endorsement of any commercial product by the National Institute of Standards and Technology is intended or implied.

This work has been carried out within the Sustainable Production Initiative and the Production Area of Advance at Chalmers University of Technology, which is gratefully acknowledged.

\section{REFERENCES}

Andersson, J., B. Johansson, A. Skoogh, and S. Leong. 2011. "Environmental Activity Based Cost Using Discrete Event Simulation." Accepted for publication In Proceedings of the 2011 Winter Simulation Conference, edited by S. Jain, R. Creasey, J. Himmelspach, K. White and M. Fu. Piscataway, New Jersey: Institute of Electrical and Electronics Engineers, Inc.

Balci, O. 1990. "Guidelines For Successful Simulation Studies.” In Proceedings of the 1990 Winter Simulation Conference, edited by O. Balci, R. P. Sadowski, and R. E. Nance, 25-32. Piscataway, New Jersey: Institute of Electrical and Electronics Engineers, Inc.

Banks, J. 1998. Handbook of Simulation. Hoboken, New Jersey: John Wiley \& Sons.

Campanelli, M., J. Berglund, and S. Rachuri. 2011. "Integration of Life Cycle Inventories Incorporating Manufacturing Unit Processes." Accepted for publication In Proceedings of the ASME 2011 International Design Engineering Technical Conference \& Computers and Information in Engineering Conference IDETC/CIE 2011. Washington, DC.

EcoProIT. 2011. Accessed June 11, 2011. http://www.ecoproit.com/.

EPD - Environmental Product Declaration. 2011. Accessed March 7, 2011. http://environdec.com/.

Haanaes, B. K., B. Balagopal, D. Arthur, M.T. Kong, I. Velken, N. Kruschwitz, et al. 2011. MIT Sloan Management Review and The Boston Consulting Group. Sustainability: The "Embracers" Seize Advantage. Massachusetts Institute of Technology.

Heilala, J., S. Vatanen, H. Tonteri, J. Montonen, S. Lind, B. Johansson, and J. Stahre. 2008. "Simulationbased Sustainable Manufacturing System Design." In Proceedings of the 2008 Winter Simulation Conference, edited by S. J. Mason, R. R. Hill, L. Mönch, O. Rose, T. Jefferson, J. W. Fowler, 19221930. Piscataway, New Jersey: Institute of Electrical and Electronics Engineers, Inc.

Hochschorner, E. and G. Finnveden. 2003. Evaluation of two simplified Life Cycle assessment methods. The International Journal of Life Cycle Assessment, 8(4): 119-128.

ISO - International Organization for Standardization. 2006a. ISO 14040: Environmental management -Life cycle assessment -- Principles and framework. ISO, Geneva.

ISO - International Organization for Standardization. 2006b. ISO 14044: Environmental management -Life cycle assessment -- Requirements and guidelines. ISO, Geneva.

ISO - International Organization for Standardization. 2006c. ISO 14025: Environmental labels and declarations -- Type III environmental declarations -- Principles and procedures. ISO, Geneva.

ISO - International Organization for Standardization. 2011 (under development). ISO 14955: Environmental evaluation of machine tools. ISO, Geneva.

Lindskog, E. and L. Lundh. 2011. "Environmental Product Footprint Assessment using Discrete Event Simulation - Proposed Method based on a Case Study at NMW." Master Thesis, Department of Product and Production Engineering, Chalmers University of Technology, Gothenburg.

Max Hamburgerrestauranger AB. 2009. “Max Annual Climate Report.” Accessed February 16, 2011. http://www.max.se/miljo.aspx.

Reap, J., F. Roman, S. Duncan, and B. Bras. 2008a. "A survey of unresolved problems in life cycle assessment." The International Journal of Life Cycle Assessment, 13(4): 290-300.

Reap, J., F. Roman, S. Duncan, and B. Bras. 2008b. "A survey of unresolved problems in life cycle assessment." The International Journal of Life Cycle Assessment, 13(5), 374-388.

Sargent, R. G. 1999. "Validation and Verification of Simulation Models." In Proceedings of the 1999 Winter Simulation Conference, edited by P. A. Farrington, H. B. Nembhard, D. T. Sturrock, and G. W. Evans, 39-48. Piscataway, New Jersey: Institute of Electrical and Electronics Engineers, Inc. 
Shao, G., D. Kibira, and K. Lyons. 2010. “A Virtual Machining Model For Sustainability Analysis.” In Proceedings of ASME 2010 International Design Engineering Technical Conference \& Computers and Information in Engineering Conference ASME CIE 2010. Montreal.

SISO - Simulation Interoperability Standards Organization, CMSD Product Development Group. 2010. Standard for: Core Manufacturing Simulation Data.

Skoogh, A. and B. Johansson. 2008. "A Methodology for Input Data Management in Discrete Event Simulation Projects." In Proceedings of the 2008 Winter Simulation Conference, edited by S. J. Mason, R. R. Hill, L. Mönch, O. Rose, T. Jefferson, J. W. Fowler, 1727-1735. Piscataway, New Jersey: Institute of Electrical and Electronics Engineers, Inc.

Skoogh, A. and B. Johansson. 2009. "Mapping of the Time-Consumption During Input Data Management Activities." Simulation News Europe, 19(2): 39-46.

\section{AUTHOR BIOGRAPHIES}

ERIK LINDSKOG is a PhD student in the field of visual production at the Department of Product and Production Development, Chalmers University of Technology, Sweden. In 2011 he obtained his M.Sc. degree in Automation and Mechatronics from the same university after completing the Master's project in the EcoProIT research project (www.ecoproit.com), together with Linus Lundh. Erik is researching mainly on how to visualize and convey information for sustainability considerations while designing and operating manufacturing systems. His email address is Erik.Lindskog@chalmers.se.

LINUS LUNDH holds a Master of Automation and Mechatronics from Chalmers University of Technology after completing his Master's project in the EcoProIT research project (www.ecoproit.com), together with Erik Lindskog. Linus is employed at Good Solutions Sweden AB to work with production data monitoring. His email address is Linus.Lundh@goodsolutions.se.

JONATAN BERGLUND holds a Master of Automation and Mechatronics from Chalmers University of Technology. He is currently working as a guest researcher at National Institute of Standards and Technology in Gaithersburg, MD, USA, while at the same time having an affiliation to Chalmers University of Technology, Division of Production Systems in Gothenburg, Sweden. Jonatan's research interest is mainly in the field of modeling sustainability aspects of production systems utilizing lifecycle assessment and Discrete Event Simulation. His email address is Jonatan.Berglund@gmail.com.

Y. TINA LEE is a computer scientist in the Manufacturing Simulation and Modeling Group at NIST. She joined NIST in 1986. Her major responsibility in recent years has been to develop information models to support various manufacturing application areas. Previously she worked at the Contel Federal Systems and at the Sperry Corporation. She received her BS in Mathematics from Providence College and MS in Applied Science from the College of William and Mary. Her email address is leet@nist.gov.

ANDERS SKOOGH is a PhD student in the field of Discrete Event Simulation at the Department of Product and Production Development, Chalmers University of Technology, Sweden. In 2005 he obtained his M.Sc. degree in Automation and Mechatronics from the same university. Anders has industrial experience in Discrete Event Simulation from his former employment as logistics developer at Volvo Car Corporation. His email address is Anders.Skoogh@chalmers.se.

BJÖRN JOHANSSON is Assistant Professor and Vice Head of Production Systems division at the Department of Product and Production Development, Chalmers University of Technology, Sweden. He serves as Production Modeling Corporation director for the European office in Gothenburg. His research interest is in the area of Discrete Event Simulation applied for manufacturing industries, including environmental effects modeling, modular modeling methodologies, software development, user interfaces, and input data architectures. His email address is Bjorn.Johansson@chalmers.se. 